\title{
Analysis on the Construction of Applied Talents Training System for Environmental Design Based on Studio System
}

\author{
Hongli Zhu, ${ }^{1, *}$ \\ ${ }^{1}$ Yunnan University of Business Management, Kunming, Yunnan 650106, China \\ *Corresponding author. Email: zhuhongli8811@163.com
}

\begin{abstract}
Establishing a perfect studio system is an important way to train environmental design professionals and one of the important platforms for the construction of environmental design professional theory and practice. The society's demand for environmental design majors is mainly based on practical application ability and hands-on operation ability. Through the "studio system" teaching mode, the establishment of environmental design professional talent training goals, the improvement of educational mechanisms, the exploration of teaching content, and the establishment of curriculum teaching systems and other content, it will be able to perfect the integration of theory and practice, and better cultivate the professional interdisciplinary talents of environmental design that can meet the needs of the market.
\end{abstract}

Keywords: Studio system, Talent training, Teaching mode, Education mechanism, Curriculum teaching system.

\section{INTRODUCTION}

Since the establishment of the environmental design major, undergraduate colleges and universities have been exploring the demand for talents in the environmental design market, and have made certain improvements in the training of environmental design professionals based on market demand. However, the current environmental design major still cannot meet the needs of the market and the requirements of enterprises to a certain extent. Therefore, many colleges and universities have begun to explore the talent training system based on the studio system. This article attempts to integrate the studio system and the talent training system, build content suitable for the cultivation of environmental design talents, and cultivate a strong regional design background that meets social needs. It is also necessary to cultivate high-quality talents with strong practical ability, analytical ability, design management ability, design marketing ability, etc., to better serve social development and create a suitable living environment for human settlements.

\section{THE NECESSITY AND PREDICAMENT OF THE STUDIO SYSTEM}

\subsection{The Necessity of Studio System}

At present, almost all enterprises hope to use experienced professional design graduates. Therefore, enterprises hope that teachers will insert practical projects in classroom teaching to cultivate students' practical operation ability and project design ability. In the process of project learning, teachers can think of ways to increase students' interest and passion, and they can also create better employment conditions for students. However, many environmental design teachers still use the traditional classroom teaching model, such as: teachers teach, students listen, and teachers assign tasks, then students complete tasks. The quality and level of talent training have been seriously affected. Many colleges and universities that have established art and design majors have begun to explore ways to reform talent training models. Under the influence of the German "Bauhaus" application-oriented education concept, many 
colleges and universities establish studios to undertake teaching and scientific research tasks, and use professional studios to undertake real design projects as a teaching carrier. The roles of teachers and students have been given new connotations, and the purpose and significance of talent training have also changed accordingly.

In addition to the cultivation of students' working ability, what is more important is the cultivation of students' practical design and handson ability. With fewer and fewer job opportunities, high-tech designers have quickly become talents needed by society. Therefore, under the new situation, it is imperative to study and explore the teaching mode that is suitable for cultivating the practical and hands-on ability of environmental design students, and to build a set of "the system of talent training in the studio system of environmental design".

\subsection{The Predicament of the Studio System}

\subsubsection{The Studio System's Project Sources Are Limited and Costly}

When the studio system is adopted, the source of the projects basically comes from teachers' projects. The types of projects are single, not rich enough, and limited to qualifications and teacher abilities. They are basically unable to undertake larger design projects. As a result, students often focus on small and medium design project exercises.

The cost and operating cost of establishing a "studio" will be relatively large, and after it is actually put into use, it needs to continue to invest in funds. It takes a lot of money and time from construction to put into use. Teachers' time and funds are difficult to guarantee. Although the school occasionally gives certain expenses and financial support, it is difficult to support the studio with the cost and quantity of the project in real operation. In addition, if they want to run the studio well, they need teachers with certain management experience and senior design capabilities.

\subsubsection{The Level of Teachers Is Uneven}

The environmental design major has its own specialties. It emphasizes the students' practical ability. It is a veritable applied discipline and major. The purpose is to use the professional theoretical knowledge learned to solve the design problems in social practice. At present, the construction of the teaching staff is not perfect, and teachers who lack corporate experience account for the majority. Most teachers graduated from undergraduates to get a master's degree and graduated from a master's degree to pursue a doctoral degree. The design projects they have done are also very limited, causing many teachers to lack practical teaching ability in design.

\section{THE IMPORTANCE OF ENVIRONMENTAL DESIGN TALENT TRAINING UNDER THE "STUDIO"}

\subsection{The Status Quo of Environmental Design Talent Training}

The teaching environment is relatively single, and teaching is often confined to the classroom. Although teachers can well grasp the progress of teaching and the control of the teaching process, teachers and students conduct knowledge and conceptual teaching and learning in a relatively fixed space environment. Students cannot directly touch the essence of practical activities. The resulting one-sided teaching leads to students' having grandiose aims but puny abilities and inability to transform concepts into practice.

\subsubsection{The Cultivation of Environmental Design Talents Lacks Characteristics}

At present, regardless of the transformation of normal universities, the transformation of singledisciplinary engineering or science, and the "college to undergraduate" and other local undergraduate colleges, almost all of them have become comprehensive universities to cultivate applied talents in environmental design. They lacks the proper types and characteristics in the positioning of talent training, and ignore the practical advantages of their own disciplines and professions.

\subsubsection{The Teaching Evaluation System Lacks Scientificity}

One of the important purposes of teaching evaluation is to improve teaching through various information feedback. However, the current teaching evaluation system of application-oriented local colleges and universities relies more on the traditional model, focusing on the combination of student evaluation and teacher evaluation combined with departmental evaluation, which is not 
objective and fair enough, and not scientific and reasonable enough.

\subsubsection{The Teaching Mode Is Simple}

The traditional teaching mode mostly adopts the knowledge transfer type teaching method, which is mainly based on the theory teaching. The student acceptance is relatively low, and the classroom atmosphere is not active. Moreover, this teaching method is not conducive to the cultivation of multiple thinking modes for environmental design students, and it is not conducive to broadening their horizons and improving their levels.

\subsection{Significance of Environmental Design Talent Training Under the "Studio"}

The "studio system" can better utilize the advantages and potential of each member, promote teamwork, and enhance the improvement of members' professional capabilities. In particular, the environmental design major belongs to the type of application-oriented talent training, which also meets the requirements of China's social and economic development and the demand for new talents in the market.

The environmental design major is a highly practical major, and the talent training must closely link the talent training model with the practical links in order to cultivate students' practical application ability. Introducing the "studio system" into the training of talents in this profession is conducive to the cultivation of applied talents and can adapt to social development.

It is a market demand to drive the cultivation of environmental design professionals with the "studio system". The teaching model has also achieved various indicators through in-depth collaboration with enterprises and full in-depth practice of teachers and students, so as to truly benefit teachers and students, and schools and enterprises. Through the "studio system" teaching mode, it is possible to establish a platform of complementary and mutual assistance among multiple disciplines and multiple majors, and provide a more open and flexible teaching environment.

\section{THE CONSTRUCTION OF THE ENVIRONMENTAL DESIGN TALENT TRAINING SYSTEM UNDER THE "STUDIO"}

\subsection{Talent Training Goals}

The essence of the environmental design training system oriented to cultivating post workers is to integrate the educational concepts and content of real projects in the studio into the whole process of talent training, to enhance the design innovation consciousness and design ability of environmental design students, and to master the basic theoretical knowledge of environmental design, environmental design related material performance and construction technology, environmental design hand-painted performance, computer performance, comprehensive performance and other related design performance techniques. The core is to cultivate high-quality compound application talents who understand design and are good at management needed for regional economic and social development.

\subsection{Improvement of Education Mechanism}

According to the teaching characteristics of the studio system, the corresponding teaching incentive mechanism, teaching sharing mechanism and teaching evaluation mechanism should be established for teaching goals.

With teaching incentive mechanism taking the studio as the main positioning, it is necessary to establish a teaching incentive mechanism based on the studio and actual projects as the content, and establish and improve the use system of the studio's special project funds, the teacher training system and the practice base construction system to provide funds, teacher support and base guarantees for the studio to carry out teaching.

It is also necessary to construct a teaching sharing mechanism based on the studio, build teaching sharing platforms, teaching sharing videos, teaching service public accounts, and teaching resource network platforms, using books, websites, WeChat public accounts, lectures, conferences, seminars, report exhibitions, classroom observations and other communication methods, disseminate actual cases in the studio and Relevant knowledge, project assignments and design cases, interpret the design methods of real design projects and the latest market demand for projects, and appreciate excellent cases, exchange teaching 
experience, report teaching results, etc. It is also a necessity to develop an open information exchange platform among teachers, integrate the project case materials mastered by various colleges and universities, realize the sharing between schools and platforms, and improve the teaching evaluation mechanism based on the studio system. What's more, it is a must to establish a scientific and effective evaluation plan: enterprises evaluate students' project design, professional education management and implementation, the schools evaluate teachers' scientific research, project introduction research, teaching research, and curriculum implementation, and the teachers evaluate students' values, learning attitudes and effects, mainly based on corporate evaluation, in order to improve students' design and practice capabilities.

\subsection{Exploration on Teaching Content}

The teaching content is divided into different studios according to market demand. For example, the drawing studio mainly addresses the performance of renderings, building roaming, basic drawing specifications, program performance, and construction drawing performance. Design studios mainly deal with design concepts and design expressions such as landscape design, interior design, furniture and furnishing design, and display design. The construction management studio mainly solves the related work of landscaping engineering, landscape construction engineering, and interior decoration engineering.

Each studio can arrange 1 person in charge and 3 to 4 teacher members. The person in charge must be a lecturer or above, or a manager or engineer with intermediate and senior titles. The person in charge is always in charge of the management and teaching organization of the studio, and the remaining teachers are responsible for the supporting teaching of professional foundation, design, practice and other content, which can be flexibly deployed in each studio according to the semester and the needs of students.

This teaching method focuses on the cultivation of students' practical ability and entrepreneurial ability, and can meet the requirements of students' individual development. In addition, it can also strengthen the cooperation and exchanges between teachers, facilitate the leading role of key teachers, give full play to the expertise of professional teachers, and enable students to obtain professional skills and entrepreneurial guidance in the process of professional learning.

\subsection{Construction of the Course Teaching System}

The curriculum system arranges corresponding courses according to the different categories of the studio, focusing on the cultivation of the ability to design positions. The studio course system is divided into three modules: theory, practical affairs, and practice. Practical affairs and practice modules account for more than $60 \%$ of the total class hours. The teaching method is mainly practice-oriented, and the practical links are highlighted in the curriculum design to encourage students to be creative in the classroom and project practice.

The faculty can be diversified, employing firstline elites from enterprises, establishing an actual project enterprise evaluation system, and extending follow-up research to students after graduation. At the same time, with the design practice innovation ability training process as the main line, the continuous design practice teaching form consisting of three stages of "design practice post recognition, design practice entrepreneurship training, and design practice post internship" runs through the whole process.

Integrating studios and actual projects into the environmental design professional teaching curriculum system of colleges and universities can enable environmental design education to go to the market and to the enterprise, which is conducive to the creation and formation of an environmental design education system with market and local characteristics. Matching, associating and combining studios and actual projects with professional teaching is the key link to achieve this goal. A two-way detailed list of "studios and actual projects" and "environmental design professional teaching content" can be established, and the points that match the professional teaching can be selected for docking. For example, living space interior design, landscape design common sense, materials and construction technology selection and application technology, green design concepts and systems, and ecological design, etc., can be respectively matched with teaching contents such as interior design, landscape design, environmental design materials and structure, environmental ecology, and environmental design history. It is necessary to implement the design based on local materials and market atmosphere. For example, in the course of "Environmental Design Materials and 
Structures", when the principle of selecting materials from local sources is explained, and the building structure and craftsmanship of wood, bamboo, soil, stone and other materials are introduced, at this time, teachers can borrow from Mr. Huang Yufeng's point of view that the traditional ecological culture education in professional education does not need to be deliberately focused, and there can always be a thing that can be done. It is a must to build a living, holographic education just as salt melts in the water and the fragrance of sandalwood radiates in the air. [5]

\subsection{Innovation in Teaching Methods}

The teaching mode with the studio system as the core is flexible and varied. Teachers can publish resources so that students can gain something before, during, and after class. For example, first, the teachers let students check books, materials, and some discussion hotspots in the network resource production class before class, so that students have a preliminary understanding and understanding of the project before class; and then teachers can use the methods of scene creation and story introduction to stimulate students' interest in learning and guide students to enter the learning state. they can implement real project design practice after class, lead students to visit, learn, reproduce and innovate on real projects, so as to realize the knowledge, understanding, practice and development of real projects. For example, in the teaching of interior design of living space, teachers can assign tasks before class. Students complete the design concepts, design methods and common design forms of interior design of living space, make report documents and communicate with students in class to deepen their understanding and application of interior design of living space. Classroom teaching can adopt the method of scenario introduction or real case introduction to show the process of actual project design, production and completion in front of students, so that students can feel the connotation of interior design and the hardships of completing the project immersively, and then further guide them analyze the characteristics of the interior design of the living space, so as to summarize the construction techniques and technical means of the interior design of the living space. As for the after-class practice session, students are required to be their future homes, which can motivate students' creativity.

\subsection{Development of Adapted Teaching Materials}

The textbook is the intuitive embodiment of the teaching purpose and teaching thinking. The contents of the real projects of the studio are reasonably incorporated into the environmental design professional textbooks, and the authenticity of the actual projects is reflected in the environmental design education of colleges and universities. According to the characteristics that real projects will continue to improve and increase, it is recommended that the curriculum materials with strong professional practical application should be electronic teaching materials, smart teaching materials, and cloud teaching materials. It is convenient to add cases based on the content of real cases and actual cases of students, and electronic files are also easy to save and disseminate.

Colleges and universities can organize related teaching forces of different faculties and majors, mainly environmental design teachers, to set up topic groups or teaching and research groups to jointly compile teaching materials. At present, most of the published environmental design textbooks are compiled using the universal environmental design theory system of the East and the West, and they are quite systematic. Only when the teaching materials of applied majors are combined with the market and the local, can they inherit the regional characteristic culture and serve the regional economic construction.

\subsection{Construction of the Faculty}

The training of environmental design teachers should be based on their own actual conditions, regard the implementation of the double-teacher quality improvement project, the high-level talent leadership project, the full-time teacher training project, and the part-time teacher team construction project as the starting point, and take the construction and cultivation of the dual-teacher team "coaching" teaching teachers and professional leaders as the focus. On the one hand, through internal training and external introduction, schools need to arrange teachers to go to the enterprises for teaching practice and strengthening the training of full-time teachers' practical ability. On the other hand, schools should formulate corresponding policies, relying on the good cooperative relationship between school and enterprise, establish a part-time teacher talent resource bank in 
the enterprise, and create a group of high-level and stable part-time teachers, so that they can build the double-qualified teaching teams capable of teaching in the "studio system" and overcome the difficulty of actual project operation in the studio.

\section{CONCLUSION}

The "studio system" teaching mode has the characteristics of openness and flexibility. It has established a cooperation platform jointly built by the school and the enterprise, which can intuitively experience the overall process of the practice project. Through long-term continuous in-depth study and practice, students often ignore the study of professional theoretical knowledge and blindly pursue the benefits brought by the results. In view of various drawbacks, it is recommended to establish an effective supervision mechanism, and have a clear understanding of the relationship between theoretical study, scientific research and corporate practice. The important thing is to consolidate the study and research of theoretical knowledge, and then complete the theoretical achievement through the studio. The real purpose of studio teaching is to make better use of theoretical knowledge to complete practice through project-based teaching.

The "studio system" teaching mode adapts to market needs, and its openness and flexibility provide teachers and students with a platform for the integration of production and education. The "studio system" environmental design professional teaching mode is still being improved. As application-oriented colleges and universities, they must adapt to school conditions and formulate practical teaching modes according to their own actual conditions, in order to cultivate comprehensive talents in environmental design that can meet the needs of the market.

\section{AUTHORS' CONTRIBUTIONS}

This paper is independently completed by Hongli Zhu.

\section{REFERENCES}

[1] Bao Rong, Xie Rongxing, The Construction of Educational System of Environmental Design Specialty at Universities [J]. Journal of Research on Education for Ethnic Minorities, 2018, 5 (29): 97-103. (in Chinese)
[2] Yu Xiaoguang, Embedding of Modern Educational Technology: A Study on the Multidimensional Inheritance of Suo Xia Changjiao Miao Culture from the Perspective of Anthropology [M]. Beijing: People's Publishing House, 2015: 103. (in Chinese)

[3] Li Xiaokun, Li Peng, Exploration on the Innovation and Development of Local Colleges and Universities under the View of Integration of Industry and Education Based on the Practice of Wenzhou University [J]. Journal of National Academy of Education Administration, 2018 (4): 53-57. (in Chinese)

[4] Liu Xianjun, Interdisciplinary as an Important Way to Build a World-class Discipline [J]. Journal of Higher Education Management, 2020, (1): 1-7. (in Chinese)

[5] Huang Yufeng, School Education and Traditional Culture [J]. Global Education, 2016, (6): 52-29. (in Chinese)

[6] McKinsey Global Institute. Manufacturing the Future: The Next Era of Global Growth and Innovation [R]. McKinsey Company, Nov. 2012.

[7] Yang Jun, Emerging Industries Are in the Ascendant, Industrial Upgrading Activates Development Potential [N]. Guangming Daily, 2015-09-20. (in Chinese) 